\title{
The Prevalence of Metabolic Syndrome and Its Components among Type 2 Diabetes Mellitus Patients at a Tertiary Hospital, Northwest Ethiopia
}

\author{
Belete Biadgo ${ }^{1 *}$, Tadele Melak ${ }^{1}$, Sintayehu Ambachew, HabtamuWondifraw \\ Baynes $^{1}$, Miteku Andualem Limenih ${ }^{2}$, Kefyalew Negerie Jaleta ${ }^{1}$, Belaynesh \\ Tachebele ${ }^{1}$, Mulugeta Melku' ${ }^{3}$, Molla Abebe ${ }^{1}$
}

\begin{abstract}
OPEN ACCESS
Citation: Belete Biadgo, Tadele Melak, Sintayehu Ambachew, et al. The Prevalence of Metabolic Syndrome and Its Components among Type 2 Diabetes Mellitus Patients at the University of Gondar Hospital, Northwest Ethiopia. Ethiop J Health Sci.2018;28 (4):645.

doi:http://dx.doi.org/10.4314/ejhs.v28i5.16

Received: January 1,2018

Accepted: January 3,2018

Published: September 1,2018

Copyright: (C) 2018 Belete Biadgo, et al.

This is an open access article distributed under the terms of the Creative Commons Attribution License, which permits unrestricted use, distribution, and reproduction in any medium, provided the original author and source are credited.

Funding: Nil

Competing Interests: The authors declare that this manuscript was approved by all authors in its form and that no competing interest exists.

Affiliation and Correspondence:

${ }^{1}$ Department of Clinical Chemistry, School of Biomedical and Laboratory Sciences, College of Medicine and Health Sciences, University of Gondar, Ethiopia

${ }^{2}$ Department of midwifery, College of Medicine and Health Sciences, University of Gondar, Ethiopia

${ }^{3}$ Department of Hematology and Immunohematology, School of Biomedical and Laboratory Sciences, College of Medicine and Health Sciences, University of Gondar, Ethiopia

*Email: beletebiadigo@yahoo.com ABSTR ACT
\end{abstract}

BACKGROUND: Metabolic syndrome is a cluster of risk factors that is responsible for the risk of coronary heart disease and stroke. Therefore, the aim of this study was to assess the prevalence of MetS and its components among T2DM patients.

METHODS: A cross-sectional study was conducted at the Diabetes Clinic of the Hospital, from June to July, 2015. Data were entered into EPI INFO software and exported to SPSS 20 for analysis. MetS prevalence was estimated using NCEP ATPIII and IDF criteria. Anthropometric measurements, investigations of serum glucose and lipid profiles were done. Logistic regression analysis was used to evaluate associated factors. A P-value $\leq 0.05$ was considered statistically significant.

RESULT: A total of 159 participants were included in the study; $119(59.7 \%)$ were females with mean $( \pm S D)$ age of (49.8 \pm 8.7$)$ year. The prevalence of MetS was $66.7 \%$ in NCEP-ATP III and $53.5 \%$ in IDF definitions. The most prevalent component of MetS was elevated triglyceride (56.6\% in ATPIII and $62.3 \%$ in IDF criteria), followed by abdominal obesity (61\%) IDF and elevated blood pressure (55.4\%) NCEP-ATPIII criteria. The regression analysis showed that increased age, being female, high BMI, having diabetes for over 5 years and poor glycemic control were significantly associated with metabolic syndrome.

CONCLUSION: The prevalence of MetS and its components among T2DM patients were high, suggesting that diabetic patients are at increased risk of CVD and other complications. Efforts should be geared towards addressing these abnormalities through lifestyle modification, health awareness and medications in order to reduce this complication.

KEYWORDS: NCEP-ATPII, IDF, Type 2 DM, Metabolic syndrome, Ethiopia, University of Gondar Hospital

\section{INTRODUCTION}

Metabolic syndrome (MetS) is a cluster of interconnected dangerous heart attack risk factors 
that directly increase the risk of cardiovascular diseases (CVD), and type 2 diabetes mellitus (T2DM). It is a highly prevalent and major public health challenge among adults in developed countries and an emerging health problem in developing countries (1).

Many international organizations and expert groups, such as the World Health Organization (WHO), the European Group for the study of Insulin Resistance, the National Cholesterol Education Program Adult Treatment Panel III (NCEP:ATPIII), the American Association of Clinical Endocrinology, the International Diabetes Federation (IDF) and the American Heart Association/National Heart, Lung and Blood Institute have endeavored to integrate all the different parameters used to define MetS. According to these expert groups, its main components are raised fasting plasma glucose, dyslipidemia and elevation of arterial blood pressure (BP), while abdominal obesity and/or insulin resistance (IR) have gained increasing attention as the core manifestations of the syndrome (2). It is estimated that around 20-25\% of the world's adult population have MetS and they are 3 times as likely to have a heart attack compared with people without the syndrome (3). The clustering CVD risk factors that illustrates MetS is now considered to be the driving force for a new CVD epidemic and people with T2DM who have MetS carry a much higher risk of CVD than those who have T2DM alonen(4).

Diabetes mellitus (DM) and related complications are associated with long-term damage and failure of various organ systems. It induces changes in the microvasculature, causing extracellular matrix protein synthesis and capillary basement membrane thickening which are the pathognomic features of diabetic microangiopathy, these changes in conjunction with advanced glycation end products oxidative stress, low grade inflammation and neovascularization of vasa vasorum can lead to vascular complications (5). Rapid urbanization and major changes in lifestyle could be driving this complications (6).

Evidence supported that nearly $70-80 \%$ of the population with DM was diagnosed with MetS (7). Dyslipidemia and other characteristics of MetS are also common in Ethiopia. In a study of $950 \mathrm{DM}$ patients in Ethiopia, the components of MetS were reported: hypertension in $46.5 \%$, obesity in $23.4 \%$ and dyslipidemia in $63.5 \%$ (8). In addition, a metaanalysis also reported $19.6 \%$ prevalence of hypertension in Ethiopian (9).

Another study in Ethiopia reported that MetS prevalence among hypertensive patients was $40.7 \%$ and $39.3 \%$ (10). The more components of the MetS that are evident, the higher is the CVD mortality rate (11). Besides, genetics, physical inactivity, ageing, a pro-inflammatory state and hormonal changes may also have a causal effect, but the role of these vary depending with ethnic group (12). A study reported higher prevalence of the MetS $(41.1 \%)$ in primary aldosteronism that confirms the negative effect of aldosterone excess on glucose metabolism (13). Currently, the prevalence of T2DM is rising in Ethiopia Therefore, the aim of the study was to determine the prevalence and components of the MetS among T2DM patients at University of Gondar Hospital, Northwest Ethiopia.

\section{METHODS AND MATERIALS}

Study design, period and area: A cross-sectional study was conducted from June to July 2015, at University of Gondar Hospital, Ethiopia. Gondar Town is located at $738 \mathrm{~km}$ far from Addis Ababa, the capital city of Ethiopia. University of Gondar Hospital plays an important role in teaching, research and community service. The hospital gives service for more than 8000 diabetic patients.

Sample size and sampling technique: The sample size was estimated based on single population proportion formula taking 95\% confidence interval (CI) and $84.8 \%$ prevalence of MetS among $\mathrm{T}_{2} \mathrm{DM}$ patients from Malaysia (14). Thus, during the study period, approximately 800 T2DM patients were estimated to visit the chronic disease clinic. Since the population during the study period was below 10,000 , the sample size correction formula was applied. Then, a total of 159 T2DM patients were included in the study. To select participants from the study population, direct patient flow was checked for one week in the chronic diseases clinic. The study participants were chosen at regular intervals from their sequence of follow-up visit using systematic random sampling techniques.

Study participants: One hundred fifty-nine T2DM patients on follow-up care at the Universityof Gondar Hospital were recruited. All T2DM patients

DOI: http://dx.doi.org/10.4314/ejhs.v28i5.16 
attending the Hospital's Chronic Illness Clinic, during the study period, were eligible to participate in the study. Participants who were pregnant, lactating mothers, patients with history of other chronic diseases and patients on treatment for lipid lowering were excluded from the study.

\section{Definition of metabolic syndrome}

IDF definition: According to IDF criteria, patients were classified as having MetS if they had abdominal obesity (waist circumference of $\geq 94 \mathrm{~cm}$ for men and $\geq 80 \mathrm{~cm}$ women) plus two of any of the following components: raised TG level $(\geq 150$ $\mathrm{mg} / \mathrm{dL})$, reduced HDL-c $(<40 \mathrm{mg} / \mathrm{dL}$ in males and $<50 \mathrm{mg} / \mathrm{dL}$ in females), raised BP (systolic BP $\geq 130$ or diastolic BP $\geq 85 \mathrm{mmHg}$ ) or treatment of previously diagnosed hypertension(3).

Modified NCEP-ATP III definition: According to the NCEP-ATP III criteria, patients were classified as having MetS if they had three or more of the following four risk factors: abdominal obesity (waist circumference $>102 \mathrm{~cm}$ in males and $>88 \mathrm{~cm}$ in females), TG $(\geq 150 \mathrm{mg} / \mathrm{dl})$, reducedHDL-c $(<40$ $\mathrm{mg} / \mathrm{dl}$ in males and $<50 \mathrm{mg} / \mathrm{dl}$ in females), higharterial BP $(\geq 130 / 85 \mathrm{mmHg})(15)$.

\section{Data collection and laboratory investigations}

Data on the characteristics of study participants:

Data on socio-demographic characteristics were collected by trained nurses from University of Gondar Hospital Chronic Illness Clinic by using semi-structured questionnaire. The data collection was conducted in accordance with the WHO STEP wise approach for non-communicable disease surveillance in developing countriesmanual (16). The systolic and diastolic BP were taken by qualified personnel using a standard mercury type analogue sphygmomanometer and stethoscope. To improve the reliability of the measurement duplicate measurements were taken from the upper arm with the hand at the heart level after the patient had been sitting for 5 minutes, and the averaged values were recorded as the final BP of the patient.

Anthropometric measurements: Anthropometric data were collected according to WHO STEPS manual (16). Weight was measured in kilograms $(\mathrm{kg})$ using the WHO weighing scale at a precision of $0.1 \mathrm{~kg}$. Height was measured using standiometer while weight was recorded after measuring the patient bare-footed and with light clothes using a weight balance. On the other hand, the height measurement is recorded to the nearest $0.1 \mathrm{~cm}$. Waist circumference (WC) in centimeter was measured at the midpoint between the lowermost rib and the iliac crest.

Laboratory investigations: Five milliliter fasting blood sample was collected in plane test tubes, and serum was extracted. The extracted serum was investigated for Glucose and lipid profile levels using Bio systems A25 (Costa Brava, Spain) automated clinical chemistry analyzer following the manufacturer's instructions. Triglycerides, HDL-c, LDL-c, total cholesterol was determined by specific enzymatic method, and glucose was determined by glucose oxidase method.

Data analysis and interpretation: Data were entered into EPI INFO computer software and exported to SPSS version 20 (IBM, USA). The data were tested for normality. Frequency distributions of the study participants were explored. Continuous variables were expressed as mean \pm standard deviation and categorical variables were expressed as percentage. Bivariate and multivariable binary logistic regression analyses were used to evaluate associated risk factors for the outcome variable. Pvalue $\leq 0.2$ was used as cutoff value to include variables for multivariable logistic regression model. The prevalence estimates for MetS were determined according to the two definitions separately. A Pvalue $\leq 0.05$ was considered statistically significant.

Data management and quality control: The quality of the data was checked for coherence and completeness. The questionnaire was pre-tested for its accuracy and consistency prior to actual data collection. Trained nurses working in the chronic diseases follow-up clinic were involved in data collection. Furthermore, the principal investigator gave feedback and corrections on daily basis to the data collectors. The proper functioning of instruments, laboratory reagents and technical performance was checked by using quality control samples. Normal and pathological control samples were run daily in order to check the optimal reactivity of the reagent and functionality of the analyzer. Therefore, to maintain the quality of the result, pre-analytical, analytical and post-analytical pre-cautions of quality were considered. Finally, the sample was processed in the clinical chemistry laboratory based on the manufacturer's manual.

\section{RESULTS}

DOI: http://dx.doi.org/10.4314/ejhs.v28i5.16 
Socio-demographic and behavioral characteristics of the participants: The study population comprised 159T2DM patients; of these, 95(59.7\%) were females. The mean $( \pm \mathrm{SD})$ age of the study participants was $(49.8 \pm 8.7)$ years. The majority, $146(91.6 \%)$, of the study participants were urban residents, and $18(21.3 \%)$ were smokers at the time of data collection (Table 1).

Table 1: Socio-demographic and behavioral characteristics according to sex of T2DM patients at the University of Gondar Hospital, Northwest Ethiopia ( $\mathrm{n}=159)$.

\begin{tabular}{|c|c|c|c|c|}
\hline Variables & Male (N \%) & Female (N \%) & Total N (\%) & P-value \\
\hline Age & & & & 0.039 \\
\hline $25-35$ & $5(25.0)$ & $15(75.0)$ & $20(12.6)$ & \\
\hline $36-46$ & $20(60.6)$ & $13(39.4)$ & $33(20.8)$ & \\
\hline $47-57$ & $22(34.9)$ & $41(65.1)$ & $63(39.6)$ & \\
\hline$\geq 58$ & $17(39.5)$ & $26(60.5)$ & $43(27.0)$ & \\
\hline Residence & & & & 0.891 \\
\hline Urban & $59(40.4)$ & $87(59.6)$ & $146(91.8)$ & \\
\hline Rural & $5(39.0)$ & $8(61.0)$ & $13(8.2)$ & \\
\hline Religion & & & & 0.452 \\
\hline Orthodox & $58(40.6)$ & $85(59.4)$ & $143(89.9)$ & \\
\hline Muslim & $3(27.3)$ & $8(72.7)$ & $11(6.9)$ & \\
\hline Protestant & $3(60.0)$ & $2(40.0)$ & $5(3.2)$ & \\
\hline Educational status & & & & 0.000 \\
\hline Illiterate & $7(16.3)$ & $36(83.7)$ & $43(27.0)$ & \\
\hline Primary school & $19(47.5)$ & $21(52.5)$ & $40(25.2)$ & \\
\hline Secondary school & $9(31.0)$ & $20(69.0)$ & $29(18.2)$ & \\
\hline College/University & $29(61.7)$ & $18(38.3)$ & $47(29.6)$ & \\
\hline Marital status & & & & 0.000 \\
\hline Single & $2(25.0)$ & $6(75.0)$ & $8(5.0)$ & \\
\hline Married & $61(58.3)$ & $60(49.6)$ & $121(76.1)$ & \\
\hline Widowed & $1(4.8)$ & $20(95.2)$ & $21(13.2)$ & \\
\hline Divorced & $0(0)$ & $9(100)$ & $9(5.7)$ & \\
\hline Occupation & & & & \\
\hline House wife & $0(0)$ & $61(100)$ & $61(38.4)$ & 0.000 \\
\hline Government worker & $28(58.3)$ & $20(41.7)$ & $48(30.2)$ & \\
\hline Non-govtal organization & $13(86.7)$ & $2(13.3)$ & $15(9.4)$ & \\
\hline Merchant & $13(59.1)$ & $9(40.9)$ & $22(13.8)$ & \\
\hline Farmer & $10(76.9)$ & $3(23.1)$ & $13(8.2)$ & \\
\hline Monthly income & & & & 0.050 \\
\hline$<1000$ & $14(29.8)$ & $33(70.2)$ & $47(29.6)$ & \\
\hline $1000-2000$ & $8(27.6)$ & $21(72.4)$ & $29(18.2)$ & \\
\hline $2001-3000$ & $14(51 . .9)$ & $13(48.1)$ & $27(17.0)$ & \\
\hline$>3001$ & $28(50.0)$ & $28(50.0)$ & $56(35.2)$ & \\
\hline Physical activity & & & & 0.045 \\
\hline Yes & $31(50.0)$ & $31(50.0)$ & $62(39.0)$ & \\
\hline No & $33(34.0)$ & $64(66.0)$ & $97(61.0)$ & \\
\hline Alcohol in the last 1 month & & & & 0.000 \\
\hline Yes & $31(66.0)$ & $16(34.0)$ & $47(29.6)$ & \\
\hline No & $33(29.5)$ & $79(69.5)$ & $112(70.4)$ & \\
\hline Current smoker & & & & 0.011 \\
\hline Yes & $13(72.2)$ & $5(27.8)$ & $18(21.3)$ & \\
\hline No & $51(36.2)$ & $90(63.8)$ & $141(88.7)$ & \\
\hline \multicolumn{5}{|l|}{ Table t. Continued.... } \\
\hline Sleeping duration $/ 24 \mathrm{hr}$ & & & & 0.48 \\
\hline 6-8 hour & $33(38.4)$ & $53(61.6)$ & $86(54.1)$ & \\
\hline
\end{tabular}

DOI: http://dx.doi.org/10.4314/ejhs.v28i5.16 


\begin{tabular}{clll}
\hline Less than 6 hour & $11(52.4)$ & $10(47.6)$ & $21(13.2)$ \\
Greater than 8 hour & $20(38.5)$ & $32(61.5)$ & $52(32.7)$ \\
Over all total & $\mathbf{6 4 ( 4 0 . 3 \% )}$ & $\mathbf{9 5 ( 5 9 . 7 \% )}$ & $\mathbf{1 5 9 ( 1 0 0 \% )}$ \\
\hline
\end{tabular}

Lipid profiles, anthropometric and clinical characteristics of T2DM patients: Among the total study participants, abnormal concentrations of total cholesterol (64.2\%), LDL-c (57.9\%), low HDL-c
(31.5\%) and high TG (62.3\%) were observed in females compared to their male counterparts (Table 2).

Table 2: Lipid profiles, anthropometric and clinical characteristics according to sex of T2DM patients at University of Gondar Hospital, northwest Ethiopia ( $\mathrm{n}=159)$.

\begin{tabular}{|c|c|c|c|c|}
\hline Variables & Male N (\%) & Female N (\%) & Total N (\%) & P-value \\
\hline Total cholesterol (mg/dl) & & & & 0.313 \\
\hline$<200$ & $33(42.9)$ & $44(57.1)$ & $77(35.8)$ & \\
\hline$\geq 200$ & $31(37.8)$ & $51(62.2)$ & $82(64.2)$ & \\
\hline LDL cholesterol (mg/dl) & & & & 0.203 \\
\hline$<130$ & $30(44.8)$ & $37(55.2)$ & $67(42.1)$ & \\
\hline$\geq 130$ & $34(37.0)$ & $58(63.0)$ & $92(57.9)$ & \\
\hline HDL Cholesterol (mg/dl) & & & & $<0.05$ \\
\hline$<40$ (men), $<50$ (women) & $22(44.0)$ & $28(56.0)$ & $50(31.5)$ & \\
\hline$\geq 40$ (men), $\geq 50$ (women) & $42(38.5)$ & $67(61.5)$ & $109(68.5)$ & \\
\hline Triglyceride (mg/dl) & & & & 0.60 \\
\hline$<150$ & 19(31.7) & $41(68.3)$ & $60(37.7)$ & \\
\hline$\geq 150$ & $45(45.5)$ & $54(54.5)$ & $99(62.3)$ & \\
\hline$\overline{\mathrm{BMI}}$ & & & & 0.901 \\
\hline Under weight & $1(33.3)$ & $2(66.7)$ & $3(1.9)$ & \\
\hline Normal weight & $29(42.7)$ & $39(57.3)$ & $68(42.8)$ & \\
\hline Over weight & $28(40.0)$ & $42(60.0)$ & $70(44.0)$ & \\
\hline Obesity & $6(33.3)$ & $12(66.7)$ & $18(11.3)$ & \\
\hline $\mathrm{SBP}(\mathrm{mmHg})$ & & & & 0.460 \\
\hline$<130$ & $31(41.3)$ & $44(58.7)$ & $75(47.2)$ & \\
\hline$\geq 130$ & $33(39.3)$ & $51(60.7)$ & $84(52.8)$ & \\
\hline $\mathrm{DBP}(\mathrm{mmHg})$ & & & & 0.558 \\
\hline$<85$ & $51(40.2)$ & $76(59.8)$ & 127(79.9) & \\
\hline$\geq 85$ & $13(40.6)$ & $19(59.4)$ & $32(20.1)$ & \\
\hline Waist circumference $(\mathrm{cm})$ & & & & $>0.05$ \\
\hline$<94$ (men), $\leq 80$ (women) & $40(30.3)$ & $26(69.7)$ & $66(41.5)$ & \\
\hline$\geq 94$ (men), $>80$ (women) & $24(25.2)$ & $69(74.2)$ & $93(58.5)$ & \\
\hline Duration of DM (in year) & & & & 0.027 \\
\hline$<5$ & $37(49.3)$ & $38(50.7)$ & $75(47.2)$ & \\
\hline$\geq 5$ & $27(32.1)$ & $57(67.9)$ & $84(52.8)$ & \\
\hline Glycemic control / FBS(mg/dl) & & & & 0.546 \\
\hline Good $(\leq 130)$ & $28(43.1)$ & $37(56.9)$ & $65(40.9)$ & \\
\hline Poor $(>130)$ & $36(38.3)$ & $58(61.7)$ & $94(59.1)$ & \\
\hline
\end{tabular}

Note: DBP: Diastolic Blood Pressure, SBP: Systolic Blood Pressure, BMI: Body Mass Index, LDL: Low density Lipoprotein, HDL: High Density Lipoprotein, mmHg: Millimeter Mercury

The prevalence of MetS and individual components of MetS based on NCEP-ATP III and IDF criteria: The overall prevalences of MetS based on NCEP-ATPIII and IDF criteria were $66.7 \%$ (95\%CI: 59.7-74.2) and 53.5\% (95\% CI: 45.3-61.0), respectively. The frequencies of MetS components were the highest for elevated TG (56.6\%) and elevated blood pressure (55.4\%) using NCEPATPIII, and central obesity $(61.0 \%)$ and elevated TG $(62.3 \%)$ in IDF criteria. The prevalence and all its individual components of MetS were higher among female in both criteria (Table 3).

DOI: http://dx.doi.org/10.4314/ejhs.v28i5.16 
Table 3: The prevalence of MetS and its components according to NCEP-ATPIII and IDF criteria among T2DM patients at University of Gondar Hospital, northwest Ethiopia ( $\mathrm{n}=159)$.

\begin{tabular}{|c|c|c|c|c|c|c|c|c|}
\hline \multirow[b]{3}{*}{ Variables } & \multicolumn{8}{|c|}{ Diagnostic definitions of Metabolic Syndrome } \\
\hline & \multicolumn{4}{|c|}{ NCEP-ATPIII criteria } & \multicolumn{3}{|c|}{ IDF criteria } & \multirow[b]{2}{*}{ P-Valuc } \\
\hline & $\begin{array}{l}\text { Male } \\
\text { N }(\%)\end{array}$ & $\begin{array}{c}\text { Female } \\
\text { N }(\%)\end{array}$ & $\begin{array}{l}\text { Total } \\
\text { N (\%) }\end{array}$ & P-value & $\begin{array}{l}\text { Male } \\
\text { N (\%) }\end{array}$ & $\begin{array}{c}\text { Female } \\
\text { N }(\%)\end{array}$ & $\begin{array}{l}\text { Total } \\
\text { N (\%) }\end{array}$ & \\
\hline Central obesity & $10(14.5)$ & $59(85.5)$ & $69(43.4)$ & 0.000 & $24(24.7)$ & $73(75.3)$ & $97(61.0)$ & 0.000 \\
\hline $\begin{array}{l}\text { Increased } \\
\text { Triglyceride }\end{array}$ & $45(45.5)$ & $54(54.5)$ & $99(56.6)$ & 0.000 & $45(45.5)$ & $54(54.5)$ & $99(62.3)$ & 0.000 \\
\hline $\begin{array}{l}\text { Low HDL } \\
\text { cholesterol }\end{array}$ & $22(42.3)$ & $30(57.7)$ & $52(32.7)$ & 0.001 & $22(42.3)$ & $30(57.7)$ & $52(32.7)$ & 0.001 \\
\hline $\begin{array}{l}\text { Elevated blood } \\
\text { pressure }\end{array}$ & $35(39.8)$ & $53(60.2)$ & $88(55.4)$ & 0.000 & $35(39.8)$ & $53(60.2)$ & $88(55.3)$ & 0.000 \\
\hline $\begin{array}{l}\text { Overall Prevalence } \\
\text { of MetS }\end{array}$ & $36(34.0)$ & $70(66.0)$ & $106(66.7)$ & $\mathbf{0 . 0 2 0}$ & $23(35.9)$ & $62(65.3)$ & $85(53.5)$ & 0.000 \\
\hline
\end{tabular}

Note: NCEP-ATPIII: National Cholesterol Education program Adult Treatment Panel III IDF: International Diabetes Federation

Clustering of components of MetSbased on NCEP-ATPIII and IDF criteria among T2DM patients: According to the NCEP-ATP III criteria, $57.5 \%$ males and $42.5 \%$ females had one additional MetS component. On the other hand, 36.7\% males and $63.3 \%$ females had 2 additional components of MetS (Table 4).

Factors associated with prevalence of MetS among T2DM patients attending at University of Gondar Hospital: The NCEP-ATP III criteria on the multivariable logistic regression analysis indicated that age $47-57$ years $(\mathrm{AOR}=9.22 ; 2.36,36.02)$, age $\geq 58$ years $(\mathrm{AOR}=9.90 ; 95 \% \mathrm{CI}: 2.19,44.72)$ and having $\mathrm{FBS}>130 \mathrm{mg} / \mathrm{dl}(\mathrm{AOR}=2.88 ; 955 \mathrm{CI}: 1.16$, 7.16) were found to have significant associations with MetS. Similarly, applying the IDF criteria for MetS, the multivariable regression analysis showed that being female $(\mathrm{AOR}=3.98 ; 95 \% \mathrm{CI}: 1.66,9.54)$, age between $47-57$ years $(\mathrm{AOR}=7.9 ; 1.63,38.41)$, age $\geq 58$ years $(\mathrm{AOR}=20.9$; 95\%CI: 3.79, 114.8), having abnormal BMI $(\mathrm{AOR}=5.12$; 95\%CI: 2.02, $12.93)$, duration of $\geq 5$ years since diagnosis of $\mathrm{T} 2 \mathrm{DM}(\mathrm{AOR}=3.14 ; 95 \% \mathrm{CI}: 1.24,7.97)$ and being FBS $>130 \mathrm{mg} / \mathrm{dl} \quad(\mathrm{AOR}=2.53 ; 95 \% \mathrm{CI}: 1.01,6.32)$ were found to have significant associations with MetS (Table 5).

Table 4: Clustering of components of MetSaccording to NCEP-ATPIII and IDF criteria among T2DM patients at University of Gondar Hospital, northwest Ethiopia ( $n=159)$.

\begin{tabular}{|c|c|c|c|c|c|c|}
\hline \multirow{3}{*}{ No of component(s) } & \multicolumn{6}{|c|}{ Diagnostic Definitions of Metabolic Syndrome } \\
\hline & \multicolumn{3}{|c|}{ NCEP-ATPIII criteria } & \multicolumn{3}{|c|}{ IDF criteria } \\
\hline & $\begin{array}{l}\text { Male } \\
\text { N (\%) }\end{array}$ & $\begin{array}{l}\text { Female N } \\
(\%)\end{array}$ & $\begin{array}{l}\text { Total } \\
\text { N (\%) }\end{array}$ & $\begin{array}{l}\text { Male } \\
\text { N (\%) }\end{array}$ & $\begin{array}{c}\text { Female } \\
\text { N (\%) }\end{array}$ & $\begin{array}{l}\text { Total } \\
\text { N (\%) }\end{array}$ \\
\hline $\mathbf{0}$ & $5(38.5)$ & $8(61.5)$ & $13(8.2)$ & $4(57.1)$ & $3(42.9)$ & $7(4.4)$ \\
\hline At least 1 & $23(57.5)$ & $17(42.5)$ & $40(25.2)$ & $19(52.8)$ & $17(47.2)$ & $36(22.6)$ \\
\hline At least 2 & $22(36.7)$ & $38(63.3)$ & $60(37.7)$ & $21(34.4)$ & $40(65.6)$ & $61(38.4)$ \\
\hline At least 3 & $11(30.6)$ & $25(69.4)$ & $36(22.6)$ & $15(35.7)$ & $27(64.3)$ & $42(26.4)$ \\
\hline At least 4 & $3(30.0)$ & $7(70.0)$ & $10(6.3)$ & $5(38.5)$ & $8(61.5)$ & $13(8.2)$ \\
\hline
\end{tabular}

Note: NCEP-ATPIII:National Cholesterol Education program Adult Treatment Panel, IDF: International Diabetes Federation

\section{DISCUSSION}

MetS is a cluster of the most dangerous heart attack risk factors: diabetes and raised fasting plasma glucose, abdominal obesity, elevated TG, low HDL and high blood pressure $(1,4)$. The overall prevalence of MetS in the study was $53.5 \%$ in IDF whereas $66.7 \%$ in the NCEP-ATPIII criteria. Previous studies also pointed out similar prevalence among T2DM population, Nigeria $62.5 \%$ (17) and 
Table 5: Bivariable and multivariable logistic regression analysis of factors associated with MetS among T2DM patients at University of Gondar Hospital, northwest Ethiopia ( $\mathrm{n}=159)$.

\begin{tabular}{|c|c|c|c|c|c|c|c|c|}
\hline \multirow[b]{2}{*}{ Variables } & \multicolumn{6}{|c|}{ NCEP-ATPIII criteria } & \multicolumn{2}{|l|}{ IDF criteria } \\
\hline & $\begin{array}{l}\text { MetS } \\
\text { N (\%) }\end{array}$ & No MetS N (\%) & $\operatorname{COR}(95 \% \mathrm{CI})$ & $\operatorname{AOR}(95 \% C I)$ & $\begin{array}{l}\text { MetS } \\
\text { N (\%) }\end{array}$ & $\begin{array}{l}\text { No MetS } \\
\text { N (\%) }\end{array}$ & COR $(95 \%$ CI) & AOR (95\%CI \\
\hline Sex Male & $36(56.3)$ & $28(43.8)$ & 1.00 & 1.00 & $23(35.9)$ & $41(64.1)$ & 1.00 & 1.00 \\
\hline Female & $70(73.7)$ & $25(26.3)$ & 2.18(1.11-4.27)* & $2.0(0.79-5.08)$ & $62(65.3)$ & $33(34.7)$ & $3.35(1.73,6.50) *$ & $3.98(1.66-9.54) *$ \\
\hline Age $25-35$ & $7(35)$ & $13(65)$ & 1.00 & 1.00 & $4(20.0)$ & $16(80.0)$ & 1.00 & 1.00 \\
\hline $36-46$ & $9(27.3)$ & $24(72.7)$ & $0.69(0.21-2.30)$ & $1.39(0.33-5.86)$ & $7(21.2)$ & $26(78.8)$ & $1.08(0.27-4.27)$ & $2.58(0.43-15.43)$ \\
\hline $47-57$ & $53(84.1)$ & $10(15.9)$ & 9.84(3.15-30.79)* & $9.22(2.36-36.02) *$ & $40(63.5)$ & $23(36.5)$ & $6.96(2.08-23.32) *$ & 7.9(1.63-38.41)* \\
\hline$\geq 58$ & $37(86.1)$ & $6(13.9)$ & $11.45(3.25-40.39) *$ & $9.90(2.19-44.72) *$ & $34(79.1)$ & $9(20.9)$ & 15.1(4.04-56.52)* & $20.9(3.79-114.8)$ \\
\hline \multicolumn{9}{|l|}{ ВМI(Kg/m2) } \\
\hline$\leq 25$ & $47(62.5)$ & $25(37.5)$ & 1.00 & 1.00 & $27(37.5)$ & $45(62.5)$ & 1.00 & 1.00 \\
\hline$>25$ & $59(67.8)$ & $28(32.2)$ & $1.12(0.58-2.17)$ & $0.76(0.30-1.95)$ & $58(66.7)$ & $29(33.3)$ & $3.33(1.74-6.40) *$ & $5.12(2.02-12.93)^{*}$ \\
\hline \multicolumn{9}{|c|}{ Duration of DM } \\
\hline$<5$ years & $36(48.0)$ & $39(52.0)$ & 1.00 & 1.00 & $25(33.3)$ & $50(66.7)$ & 1.00 & 1.00 \\
\hline$\geq 5$ years & $70(83.3)$ & $14(16.7)$ & $5.42(2.61-11.25) *$ & $2.63(1.00-6.93)$ & $60(71.4)$ & $24(28.6)$ & $5.0(2.548-9.813) *$ & 3.14(1.24-7.97)* \\
\hline \multicolumn{9}{|l|}{ FBS(mg/dl) } \\
\hline$\leq 130$ & $29(44.6)$ & $36(55.4)$ & 1.00 & 1.00 & $23(35.4)$ & $42(64.6)$ & 1.00 & 1.00 \\
\hline$>130$ & $77(81.9)$ & $17(18.1)$ & $5.62(2.74-11.52) *$ & $2.88(1.16-7.16) *$ & $62(66.0)$ & $32(34.0)$ & 3.54(1.82-6.87)* & $2.53(1.01-6.32) *$ \\
\hline \multicolumn{9}{|c|}{ Physical activity } \\
\hline Yes & $33(45.8)$ & $39(54.2)$ & 1.00 & 1.00 & $27(37.5)$ & $45(62.5)$ & 1.00 & 1.00 \\
\hline No & $73(83.9)$ & $14(16.1)$ & $6.16(2.95-12.87) *$ & $0.42(0.17-1.07)$ & $58(66.7)$ & $29(33.3)$ & $3.33(1.74-6.40) *$ & $0.63(0.26-1.55)$ \\
\hline \multicolumn{9}{|c|}{ Alcohol in the last 1 month } \\
\hline Yes & $70(73.7)$ & $25(26.3)$ & 2.18(1.11-4.27)* & $2.04(0.81-5.15)$ & $52(54.7)$ & $43(45.3)$ & $1.14(0.60-2.14)$ & $1.05(0.42-2.58)$ \\
\hline No & $36(55.4)$ & $28(44.6)$ & 1.00 & 1.00 & $33(50.8)$ & $31(49.2)$ & 1.00 & 1.00 \\
\hline \multicolumn{9}{|c|}{ Sleeping duration $/ 24 \mathrm{hr}$} \\
\hline $6-8$ hour & $49(57.0)$ & $37(43.0)$ & 1.00 & 1.00 & $41(47.8)$ & $45(52.3)$ & 1.00 & 1.00 \\
\hline$<6$ hour & $17(81.0)$ & $4(19.0)$ & $3.21(0.99-10.33)$ & $1.49(0.33-6.81)$ & $10(47.6)$ & $11(52.4)$ & $0.99(0.38-2.59)$ & $0.83(0.23-3.03)$ \\
\hline$>8$ hour & $40(76.9)$ & $12(23.1)$ & $2.52(1.16-5.46) *$ & $1.01(0.36-2.85)$ & $34(63.4)$ & $18(34.6)$ & $2.07(1.02-4.22) *$ & $1.67(0.61-4.58)$ \\
\hline
\end{tabular}

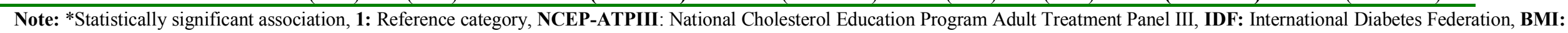
Body Mass Index, FBS: Fasting Blood Sugar, AOR: Adjusted Odds Ratio, COR: Crude Odds Ratio, CI: Confidence Interval 
Ghana 58\%(18). Conversely, higher rate of MetS than the finding of this study was reported among DM patients $70-80 \%$ (7), 76\% in Abbottabad (19) according to NCEP-ATPIII and $66 \%$ based on IDF criteria (20). Other previous studies also reported higher prevalence of MetS in Nepalese $(73.9 \%)$ and (66.8\%) (21), Malaysia (96.1\%), (84.8\%) (14) T2DM patients according to NCEP ATP III and IDF definitions, respectively.

Lower prevalence of MetS was reported in T2DM patients in Bosnia and Herzegovina (47.91\%) (22), in Ethiopian hypertensive patients (40.7\%) and (39.3\%) (10) using NCEP-ATPII and IDF criteria respectively. These differences in the prevalence of MetS can be explained by the interaction of genetic and environmental factors, rapid urbanization and the adoption of unhealthy lifestyle which predispose individuals to different risk factors of MetS (6).

The prevalence of the MetS is strongly dependent on the different cut-off points and sets of criteria used by different definitions. In this study, slightly higher prevalence of MetS was observed by ATP III definition in comparison with IDF $(66.7 \%$ vs. $53.5 \%)$. It could be attributed to the relative flexibility of the ATP III in which abdominal obesity is not considered as a prerequisite for the diagnosis and to the fact that criteria are more broadly focused on specific cardiovascular risk factors. Although it has been well understood that the international anthropometric cutoffs for detection of body fatness and risk of MetS are not appropriate for Ethiopians and some Asian countries to determine MetS.Ethiopians have higher body fat at a relatively low BMI because of the slender body frame compared with a Caucasians or black person from another country which predisposes them to very higher risk of MetS, T2DM and CVD than any other population in the world (23). Except for this difference, the ATP III and IDF definitions are essentially fair as seen by the degree of agreement (kappa statistic $=0.472$ ) which is in agreement with the Bangladesh study (24).

In this study, central obesity and hypertriglyceridemia were most prevalent components of the MetS in agreement to a study in Ethiopia (8). This finding is not surprising given the observation that central obesity plays a key role in the development of the MetS and appears to precede the appearance of the other MetS components. However, it is pertinent to note that although the specific role of central obesity in patients with the MetS remains unexplained; active brown adipocytes which accumulate in central locations have been found to be metabolically active. A small proportion T2DM have all the components of the MetS in this study. This is in contradistinction to the report (25) who reported the absence of a combination of four components of MetS in their study participants.

The frequency of individual MetS components were predominantly higher in females compared to males in both criteria with central obesity and hypertriglyceridemia predominantly elevated. It is consistent with the report of an earlier study (26) but conflicting with studies in Nepal which identfied central obesity as the most prevalent and hypertension as the least prevalent components of MetS $(21,27)$.

From multivariable analysis, participants who had high BMI, longer duration of illness since T2DM diagnosis, age, sex and having poor glycemic control are significantly associated with MetS. There were variations in the prevalence of each of the distinct risk factors of MetS by sex. For instance, previous studies supported a significantly elevated body weight, WC, and low HDL-cholesterol, hypertensive, dyslipidemia and poor glycemic control observed in women than men $(10,26)$. The observation of sex difference in body fat distribution, IR, sex hormones and the effect of glucose, pro-inflammatory state, decreased growth hormone secretion, hypogonadism and stress induced hyper-cortisolism could have casual effects although the role of these may vary depending on ethnic group (12). Spectacular advances in evidence based medicine have shown that diabetic middle aged women are 8 times more likely to develop cardiovascular events than non-diabetic (28). According to a large population survey conducted, female diabetics were more obese compared to male diabetics $(13 \%$ and $10 \%$, respectively) (29).

In our study, patients with MetS were sharply increased in the age groups of $\geq 58$ years in both men and women, which was quite expected and supported by another study (8). On the contrary, a study reported that there is a sharp decline of the prevalence at very high age group due to increased frequency of death of individuals who were most susceptible to obesityrelated mortality such as $\mathrm{CAD}$ and cerebrovascular events (30).

In this study, durations of illness and glycemic control were significantly associated with MetS which is supported by previous studies which reported that participants who had diabetes for over 5 years were found to have an 11.3 times risk of developing MetS (31). This is contrary to other findings (32) in which the prevalence of MetS decreased along with an increase in the duration of diabetes. Another study also found an association of the MetS with less duration of diabetes (33). This might be due to decreased BMI as a result of

DOI: http://dx.doi.org/10.4314/ejhs.v28i5.16 
medical intervention and better metabolic control, increasing awareness with the longer duration illness in DM patients. The association of the MetS with poor glycemiccontrol could be the result of lack of awareness and inadequate access to quality medical care. This is supported by a study in Ghana which reported that dyslipidemia and MetS were associated with poor glycemic control (34).

In this study, patients with longer duration of sleeping had a risk of developing MetS. However, it was not a significant predictor of the MetS in our multivariable logistic regression model. Epidemiological studies, consistently to our study, showed that long sleep duration was associated with MetS (35). A meta-analysis of observational studies indicated that short and long sleep durations are risky behaviors for increasing the risk of MetS (36). On the contrary, a number of studies in adults demonstrated an association between short sleep duration and MetS (3739). The limitation of this study was its cross-sectional nature amongst patients which limits our causal inference.

The prevalence of MetS and its components using NCEP-ATPIII and IDF criteria amongst persons with T2DM was high. Longer duration of DM, poor glycemic control, high BMI, increased age and female sex were significantly associated with MetS. Education on appropriate glycemic control and healthy life style modification should be provided to control and reduce diabetes-related morbidity and mortality.

\section{REFERENCES}

1. Eckel RH, Alberti K, Grundy SM, Zimmet PZ. The metabolic syndrome. The lancet. 2010;375(9710):181-3.

2. Kassi E, Pervanidou P, Kaltsas G, Chrousos G. Metabolic syndrome: definitions and controversies. BMC medicine. 2011;9(1):1.

3. Alberti KGMM, Zimmet P, Shaw J. Metabolic syndrome a new world wide definition. A consensus statement from the international diabetes federation. Diabetic medicine. 2006;23(5):469-80.

4. Unwin N, Gan D, Whiting D. The IDF Diabetes Atlas: providing evidence, raising awareness and promoting action. Diabetes research and clinical practice. 2010;87(1):2.

5. 5. Chawla A, Chawla R, Jaggi S. Microvasular and macrovascular complications in diabetes mellitus: Distinct or continuum? Indian journal of endocrinology and metabolism. 2016;20(4):546.

6. Mbanya JCN, Motala AA, Sobngwi E, Assah FK, Enoru ST. Diabetes in sub-saharan africa. The lancet. 2010;375(9733):2254-66.

DOI: http://dx.doi.org/10.4314/ejhs.v28i5.17
7. Marchesini G, Forlani G, Cerrelli F, Manini R, Natale S, Baraldi L, et al. WHO and ATPIII proposals for the definition of the metabolic syndrome in patients with Type 2 diabetes. Diabetic medicine. 2004;21(4):383-7.

8. Tamiru S, Alemseged F. Risk factors for cardiovascular diseases among diabetic patients in southwest Ethiopia. Ethiopian journal of health sciences. 2010;20(2).

9. Kibret KT, Mesfin YM. Prevalence of hypertension in Ethiopia: a systematic metaanalysis. Public Health Reviews. 2015;36(1):1.

10. Tachebele B, Abebe M, Addis Z, Mesfin N. Metabolic syndrome among hypertensive patients at University of Gondar Hospital, North West Ethiopia: a cross sectional study. $B M C$ cardiovascular disorders. 2014;14(1):1.

11. Hu G, Qiao Q, Tuomilehto J, Balkau B, BorchJohnsen K, Pyorala K. Prevalence of the metabolic syndrome and its relation to all-cause and cardiovascular mortality in nondiabetic European men and women. Archives of internal medicine. 2004;164(10):1066-76.

12. Anderson P, Critchley J, Chan J, Cockram C, Lee $Z$, Thomas G, et al. Factor analysis of the metabolic syndrome: obesity vs insulin resistance as the central abnormality. International journal of obesity. 2001;25:1782-8.

13. Fallo F, Veglio F, Bertello C, Sonino N, Della Mea P, Ermani M, et al. Prevalence and characteristics of the metabolic syndrome in primary aldosteronism. The Journal of Clinical Endocrinology \& Metabolism. 2006;91(2):454-9.

14. Tan MC, Ng OC, Wong TW, Joseph A, Chan YM, Hejar AR. Prevalence of metabolic syndrome in type 2 diabetic patients: A comparative study using WHO, NCEP ATP III, IDF and Harmonized definitions. Health. 2013;5(10):1689-96.

15. Heng D, Ma S, Lee JJ, Tai BC, Mak KH, Hughes $\mathrm{K}$, et al. Modification of the NCEP ATP III definitions of the metabolic syndrome for use in Asians identifies individuals at risk of ischemic heart disease. Atherosclerosis. 2006;186(2):36773.

16. Organization WH. WHO STEPS surveillance manual: the WHO STEPwise approach to chronic disease risk factor surveillance. 2005.

17. Unadike BC, Akpan NA, Peters EJ, Essien IO, Essien OE. Prevalence of the Metabolic Syndrome among Patients with Type 2 Diabetes Mellitus in UYO, Nigeria. African Journal of Endocrinology and Metabolism. 2009;8(1):1-9.

18. Nsiah K, Shang VO, Boateng KA, Mensah FO. Prevalence of metabolic syndrome in type 2 
diabetes mellitus patients. Int $J$ App Basic Med Res. 2015;5:133-38.

19. Ahmed N, Ahmad T, Hussain SJ, Javed M. Frequency of Metabolic Syndrome in Patients with Type-2 Diabetes J Ayub Med Coll Abbottabad. 2010;22(1):139-42.

20. Ipadeola A, Adeleye J. The metabolic syndrome and accurate cardiovascular risk prediction in persons with type 2 diabetes Mellitus. Diabetes \& Metabolic Syndrome: Clinical Research \& Reviews. 2016;10(1):7-12.

21. 21. Pokharel DR, Khadka D, Sigdel M, Yadav NK, Acharya S, Kafle RC, et al. Prevalence of metabolic syndrome in Nepalese type 2 diabetic patients according to WHO, NCEP ATP III, IDF and Harmonized criteria. Journal of Diabetes \& Metabolic Disorders. 2014;13:104.

22. Music M, Dervisevic A, Pepic E, Lepara O, Fajkic A, AscicButurovic B, et al. Metabolic Syndrome and Serum Liver Enzymes Level at Patients with Type 2 Diabetes Mellitus. Med Arh. 2015;69(4):251-5.

23. Deurenberg P, Yap M, vanStaveren WA. Body mass index and percent body fat: a meta-analysis among different ethnic groups. Int $J$ Obes Relat Metab Disord. 1998;22:1164.

24. Akhter M, Ahmed A, Rahman M, Malek R, Alam A, Hoque M. Prevalence of metabolic syndrome in non-obese newly detected Type-2 diabetes Mellitus. Bangabandhu Sheikh Mujib Medical University Journal. 2016;9(1):26-31.

25. Fezeu L, Balkau B, Kengne A-P, Sobngwi E, Mbanya J-C. Metabolic syndrome in a sub-Saharan African setting: central obesity may be the key determinant. Atherosclerosis. 2007;193(1):70-6.

26. Okafor CI. The metabolic syndrome in Africa: current trends. Indian journal of endocrinology and metabolism. 2012;16(1):56.

27. 27. Bhattarai S, Kohli SC, Sapkota S. Prevalence of metabolic syndrome in type 2 diabetes mellitus patients using NCEP/ATP III and IDF criteria in Nepal. Nepal J Med Sci. 2012;1:798.

28. Yu MK, Lyles CR, Bent-Shaw LA, Young BA. Sex disparities in diabetes process of care measures and self-care in high-risk patients. Journal of diabetes research. 2013;2013.

29. Alamgir MA, Javid RA, Hameed A, Mustafa I. Gender difference in components of metabolic syndrome among patients of Type 2 diabetes.
Pakistan journal of medical sciences. 2015;31(4):886.

30. Deepa M, Farooq S, Datta M, Deepa R, Mohan V. Prevalence of metabolic syndrome using WHO, ATP III and IDF definitions in Asian Indians: the Chennai Urban Rural Epidemiology Study (CURES-34). Diabetes Metab Res Rev. 2007;23:127-34

31. Mogre V, Salifu ZS, Abedandi R. Prevalence, components and associated demographic and lifestyle factors of the metabolic syndrome in type 2 diabetes mellitus. Journal of Diabetes \& Metabolic Disorders. 2014;13(1):1.

32. Shimajiri Y, Tsunoda K, Furuta M, Kadoya Y, Yamada S, Nanjo K, et al. Prevalence of metabolic syndrome in Japanese type 2 diabetic patients and its significance for chronic vascular complications. Diabetes research and clinical practice. 2008;79(2):310-7.

33. Abdul-Ghani M, Nawaf G, Fawaz G, Itzhak B, Minuchin O, Vardi P. Increased prevalence of microvascular complications in type 2 diabetes patients with the metabolic syndrome. IMAJRAMAT GAN. 2006;8(6):378.

34. Titty F. Glycaemic control, dyslipidaemia and metabolic syndrome among recently diagnosed diabetes mellitus patients in Tamale Teaching Hospital, Ghana. West African journal of medicine. 2010;29(1).

35. Arora T, Jiang CQ, Thomas GN, Lam KB, Zhang WS, Cheng KK, et al. Self-reported long total sleep duration is associated with metabolic syndrome: the Guangzhou Biobank Cohort Study. Diabetes care. 2011;34:2317-9.

36. 36. S-Y Ju, W-S C. Sleep duration and metabolic syndrome in adult populations: a metaanalysis of observational studies. Nutrition \& Diabetes. 2013;3:e65:1-9.

37. Choi JK KM, Kim JK, Park JK, Oh SS, Koh SB et al. Association between short sleep duration and high incidence of metabolic syndrome in midlife women. Tohoku J Exp Med. 2011;225:187-93.

38. Katano S, Nakamura Y, Nakamura A, Murakami Y, Tanaka T, Takebayashi T, et al. Relationship between sleep duration and clustering of metabolic syndrome diagnostic components. Diabetes Metab Syndr Obes. 2011;4:119-25.

39. Kobayashi D, Takahashi O, Deshpande G, Shimbo T, Fukui T. Relation between metabolic syndrome and sleep duration in Japan: a large scale crosssectional study. Intern Med. 2011;50:103-7.

DOI: http://dx.doi.org/10.4314/ejhs.v28i5.16 